\title{
Influence of rolling schedule on characteristics of thermomechanically treated $\mathrm{CuBe} 2$ alloy
}

\author{
S NESTOROVICH, D MARKOVICH and D GUSKOVICH \\ University of Belgrade, Technical Faculty Bor, 19210 Bor, Yugoslavia \\ MS received 4 November 1996
}

\begin{abstract}
Thermomechanical treatment of $\mathrm{CuBe} 2$ alloy was performed as follows: quenching, primary ageing, cold rolling and secondary ageing at different temperatures. The cold rolling was carried out following two deformation schedules (with different intensity of deformation). The investigation results on influence of deformation intensity and secondary ageing temperature on hardness, electrical conductivity, structure and activation energy on thermomechanically treated $\mathrm{CuBe} 2$ alloy are presented.

It was found that the deformation intensity had the greatest influence on hardness upon secondary ageing at $270^{\circ} \mathrm{C}$. A hardness of $470 \mathrm{HV}$ was attained by use of higher deformation intensity schedule while a hardness of $390 \mathrm{HV}$ was attained with lower deformation intensity schedule.
\end{abstract}

Keywords. Deformation schedule; thermomechanical treatment; ageing.

\section{Introduction}

The results of investigations of the ageing kinetics and studies on precipitation stages of $\mathrm{CuBe} 2$ alloy are given in a large number of works. Mainly, there is an agreement that the precipitation process from solid solution occurs both continuously and discontinuously. The prevailing mechanism depends on many factors like ageing temperature (Bonfield and Edwards 1974; Rioja and Laughlin 1980) and degree of previous deformation (Bonfield and Edwards 1974; Kreye 1971).

It is also known that the structural changes, introduced during primary ageing (Pastuhova et al 1977) and deformation (Kreye 1971), have the basic role in precipitate formation during secondary ageing. Hence it is expected that the differences in structure, obtained by different intensity deformation, will appear later upon secondary ageing.

The aim of this work is to investigate the influence of deformation intensity and secondary ageing temperature on hardness, electrical conductivity and structure of thermomechanically treated $\mathrm{CuBe} 2$ alloy. Their influence on the deformation degree and activation energy of ageing process of $\mathrm{CuBe} 2$ alloy are also studied.

\section{Experimental}

CuBe 2 alloy with $98 \mathrm{wt} \% \mathrm{Cu}$ and $2 \mathrm{wt} \% \mathrm{Be}$, was obtained by melting in vacuum from pure components. After casting, the homogenization annealing of $24 \mathrm{~h}$ at temperature $800^{\circ} \mathrm{C}$ was carried out. Then the alloy was rolled into plate thicknesses of $0.875,1 \cdot 16$, 1.75 and $3.5 \mathrm{~mm}$. The rolled plates were subjected to solutionizing treatment at $780^{\circ} \mathrm{C}$ in nitrogen protective atmosphere for $30 \mathrm{~min}$ and quenched in water. After quenching, the primary ageing was carried out at $200^{\circ} \mathrm{C}$ for $60 \mathrm{~min}$ for $\mathrm{G}$. P. zones formation 
(Zhu et al 1986; Rioja and Laughlin 1980). After primary ageing the specimens were cold rolled according to two deformation schedules (Celikov 1968) with four degrees of deformation for each schedule: $20,40,60$ and $80 \%$, on final thickness of $0.7 \mathrm{~mm}$. The first schedule, denoted $\mathrm{D}_{5}$, in which the ratio of the length of the arc of a roll contact $l_{\mathrm{a}}$ to the mean height of the metal $h_{\mathrm{m}}$ in the deformation zone: $l_{\mathrm{a}} / h_{\mathrm{m}} \geqslant 5$. The second schedule $\mathrm{D}_{1}$, with the ratio $l_{\mathrm{a}} / h_{\mathrm{m}}=1$. The average strain rate in both cases was constant and equal to $0.73 \mathrm{~s}^{-1}$.

Deformation schedule with low intensity $\mathrm{D}_{1}$ was obtained in the conditions of small reductions at each pass $(2-10 \%$, table 1$)$. Deformation schedule with high intensity $D_{5}$ was obtained in conditions of great reductions at each pass $(20-50 \%$, table 2$)$. Table 3 gives details of passes number, deformation degree and mechanical procedure of rolling. After cold rolling the secondary ageing at 270 and $340^{\circ} \mathrm{C}$ was carried out.

The obtained samples were tested for hardness and electrical conductivity. Metallographic examination and estimation of activation energy were also conducted.

Activation energy examination was carried out on cold rolled samples by the method of differential thermal analysis (DTA). Kinetics method was used for activation energy evaluation (Borchardt and Daniels 1957).

Metallographic analysis of aged samples was carried out by using optical microscopy.

Table 1. Pass sequence for deformation schedule $D_{1}$ for reduction of $80 \%$.

\begin{tabular}{lcccc}
\hline $\begin{array}{l}\text { No of } \\
\text { passes }\end{array}$ & $\begin{array}{c}h \\
(\mathrm{~mm})\end{array}$ & $\begin{array}{c}\Delta h \\
(\mathrm{~mm})\end{array}$ & $\begin{array}{c}\varepsilon_{\mathrm{h}} \\
(\%)\end{array}$ & $\begin{array}{c}D_{1}= \\
l_{\mathrm{a}} / h_{\mathrm{m}}\end{array}$ \\
\hline 0 & 3.50 & - & - & - \\
1 & 3.15 & 0.35 & 10.00 & 1.00 \\
2 & $2 \cdot 85$ & 0.30 & $9 \cdot 50$ & 1.02 \\
3 & 2.60 & 0.25 & 8.77 & 1.00 \\
4 & 2.40 & 0.20 & 7.69 & 1.01 \\
5 & 2.23 & 0.17 & 7.08 & 1.00 \\
$\ldots$ & $\ldots$ & $\ldots$ & $\ldots$ & $\ldots$ \\
31 & 0.778 & 0.022 & 2.50 & 1.01 \\
32 & 0.759 & 0.019 & 2.40 & 1.01 \\
33 & 0.741 & 0.018 & 2.37 & 1.01 \\
34 & 0.724 & 0.017 & 2.29 & 1.01 \\
35 & 0.708 & 0.016 & 2.20 & 1.01 \\
36 & 0.700 & 0.008 & 1.12 & 1.01 \\
\hline
\end{tabular}

Table 2. Pass sequence for deformation schedule $D_{5}$ for reduction of $80 \%$

\begin{tabular}{lcccc}
\hline $\begin{array}{l}\text { No of } \\
\text { passes }\end{array}$ & $\begin{array}{c}h \\
(\mathrm{~mm})\end{array}$ & $\begin{array}{c}\Delta h \\
(\mathrm{~mm})\end{array}$ & $\begin{array}{c}\varepsilon_{\mathbf{h}} \\
(\%)\end{array}$ & $\begin{array}{c}D_{5}= \\
l_{\mathbf{a}} / h_{\mathbf{m}}\end{array}$ \\
\hline 0 & $3 \cdot 50$ & - & - & - \\
1 & 1.80 & $1 \cdot 70$ & $48 \cdot 5$ & $5 \cdot 07$ \\
2 & 1.25 & 0.55 & $30 \cdot 5$ & $5 \cdot 01$ \\
3 & 0.96 & 0.29 & 23.5 & 5.02 \\
4 & 0.78 & 0.18 & 18.75 & 5.02 \\
5 & 0.70 & 0.08 & $10 \cdot 30$ & 3.95 \\
\hline
\end{tabular}


Table 3. Correlation of number of passes, reduction degree and deformation schedule.

\begin{tabular}{lccccc}
\hline \multirow{2}{*}{$\begin{array}{l}\text { Total deformation } \\
\text { degree }\end{array}$} & \multicolumn{2}{c}{ No of passes for schedule } & \multicolumn{2}{c}{ Thickness (mm) } \\
\cline { 2 - 3 } \cline { 5 - 6 } & $\mathrm{D}_{1}$ & $\mathrm{D}_{5}$ & & Before rolling & After rolling \\
\hline 20 & 9 & 1 & & 0.875 & 0.7 \\
60 & 18 & 3 & & 1.16 & 0.7 \\
80 & 27 & 4 & & 1.75 & 0.7 \\
80 & 36 & 5 & & 3.50 & 0.7 \\
\hline
\end{tabular}

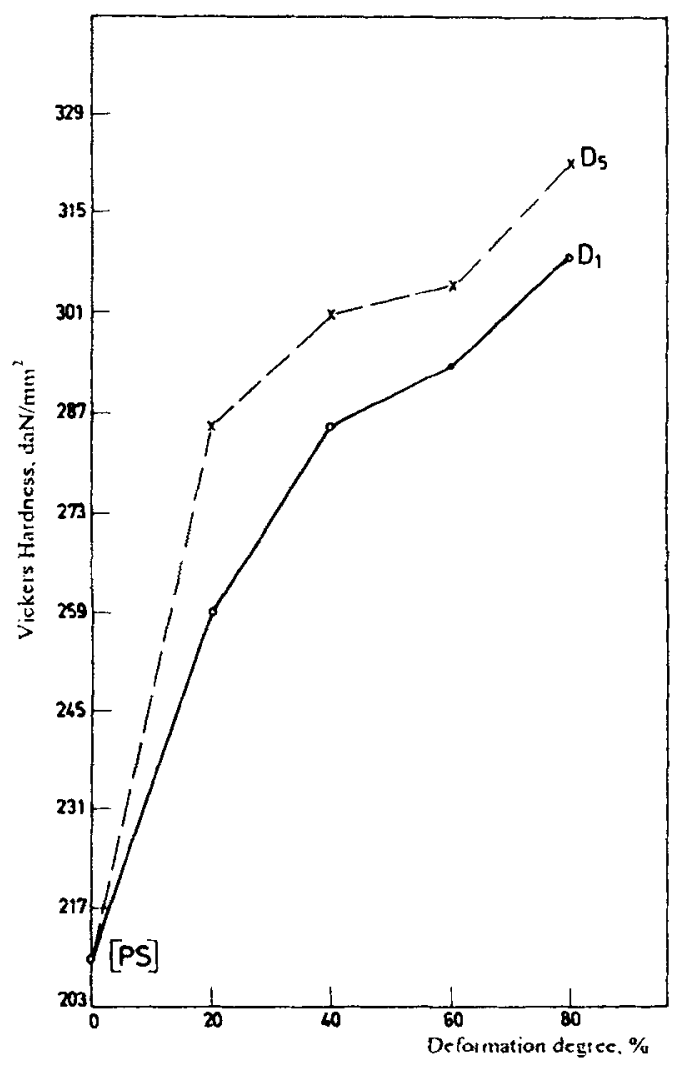

Figure 1. Dependence of hardness on deformation degree after cold rolling of primary aged alloy.

\section{Results and discussion}

Hardness of primary aged alloy during cold rolling increases with cold deformation degree due to deformation strengthening. Some higher hardness values were obtained for deformation schedule $D_{5}$ (figure 1 ).

After rolling and secondary ageing of alloy at $270^{\circ} \mathrm{C}$ hardness considerably increases and attains $470 \mathrm{HV}$ for $\mathrm{D}_{5}$ schedule and $390 \mathrm{HV}$ for $\mathrm{D}_{1}$ schedule at deformation degree 
of $80 \%$ (figure 2). Hardness of about $350 \mathrm{HV}$ was obtained by secondary ageing at $340^{\circ} \mathrm{C}$ without previous deformation (ordinate on figure 3), and introduction of deformation leads to decrease of hardness after secondary ageing at this temperature (figure 3 ).

By metallographic analysis the difference in mode of the precipitation after secondary ageing, depending on previous deformation schedule, was established. Characteristic discontinuous precipitate obtained by two-stage alloy ageing at $270^{\circ} \mathrm{C}$, without previous deformation, is shown on figure 4 . Discontinuous precipitate is observed at original boundaries of undeformed grain. The precipitation occurs mainly on the visible shear bands in samples rolled by $D_{1}$ schedule (figure 5 ). The deformation bands are not so visible in samples rolled by $D_{5}$ schedule, and the precipitate occurred both over shear bands and total grain volume (figure 6).

Electrical conductivity of cold rolled samples decreases with deformation degree and it is the lowest for $80 \%$ deformation degree for both used deformation schedules (figure 7). After secondary ageing at $270^{\circ} \mathrm{C}$, the electrical conductivity increases with increase in the degree of deformation and it is higher for more intensive deformation schedule $\mathrm{D}_{5}$ (figure 8 ). Electrical conductivity of secondary aged alloy at $340^{\circ} \mathrm{C}$ is 24-26MS/m for both deformation schedules (figure 9).

It should be kept in mind, in interpretation of these results, that relatively less number of slip systems is activated in rolling by low intensity deformation schedule $\mathrm{D}_{1}$,

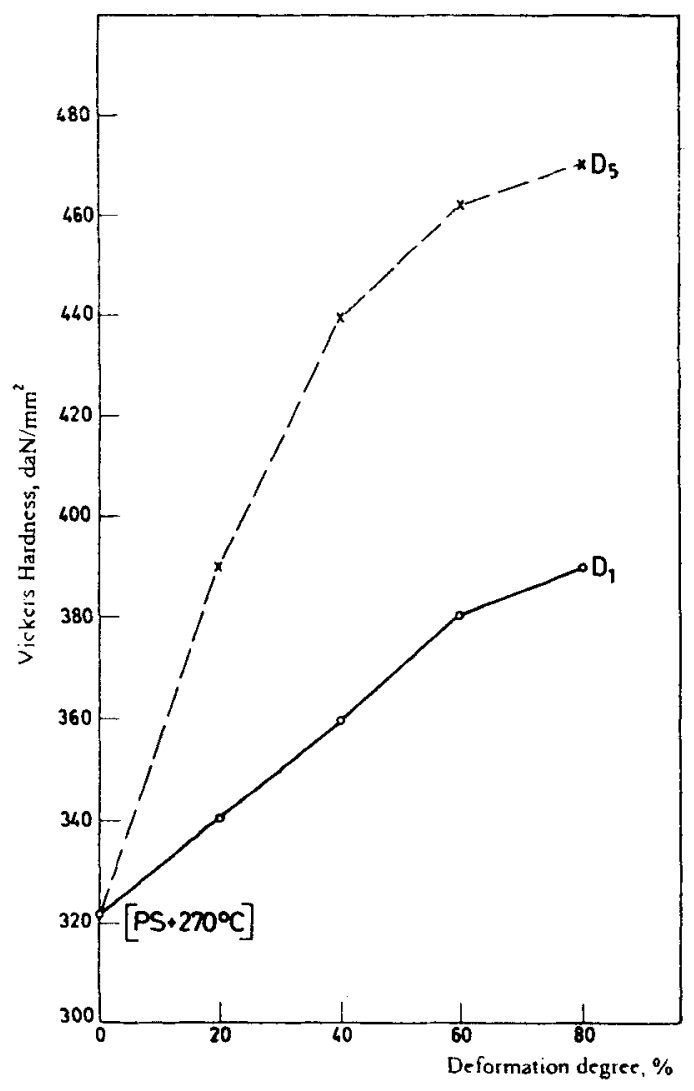

Figure 2. Dependence of hardness on deformation degree after secondary ageing at temperature $270^{\circ} \mathrm{C}$. 


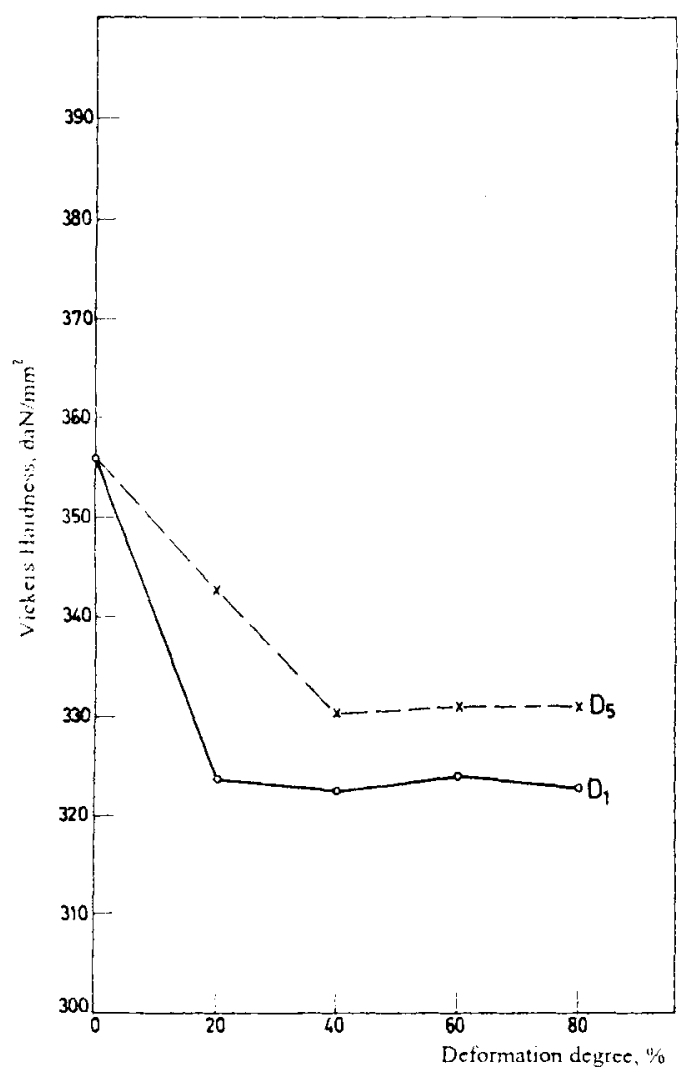

Figure 3. Dependence of hardness on deformation degree after secondary ageing at temperature $340 \mathrm{C}$.

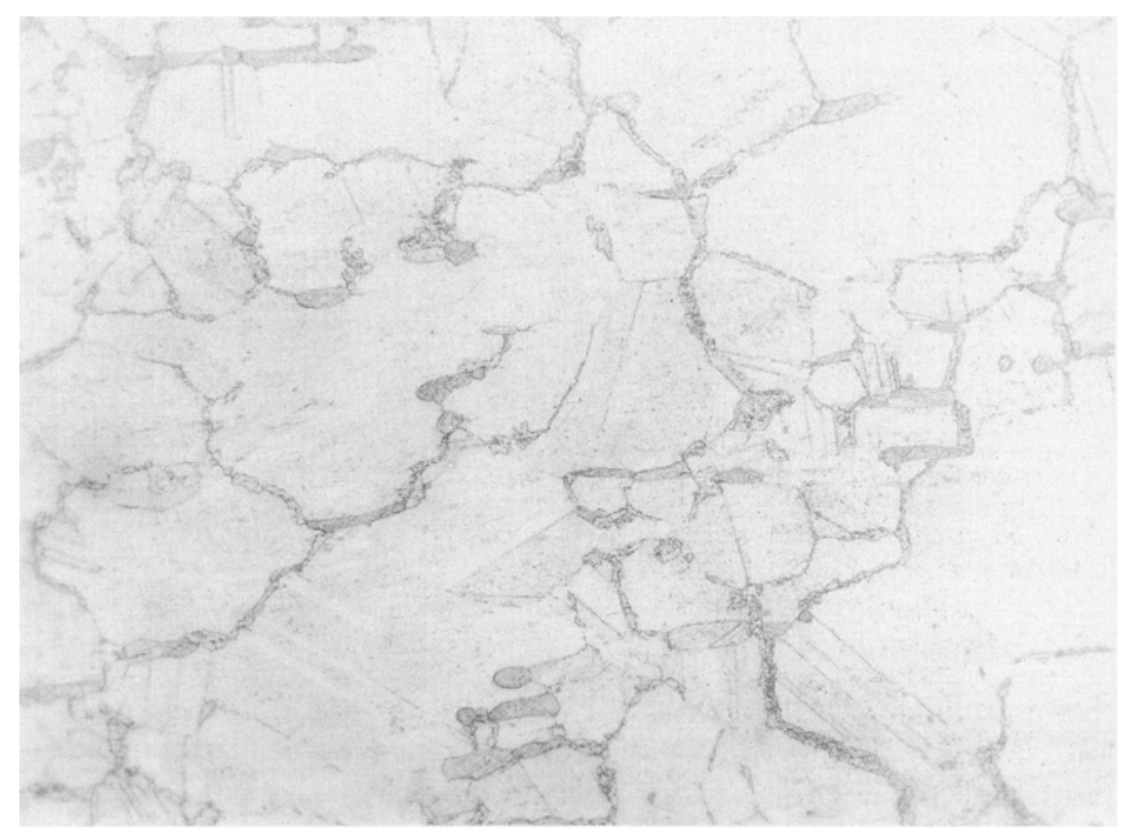

Figure 4. Discontinuous precipitation at original grain boundary for sample primary aged + secondary aged at $270 \mathrm{C}(\times 300)$. 


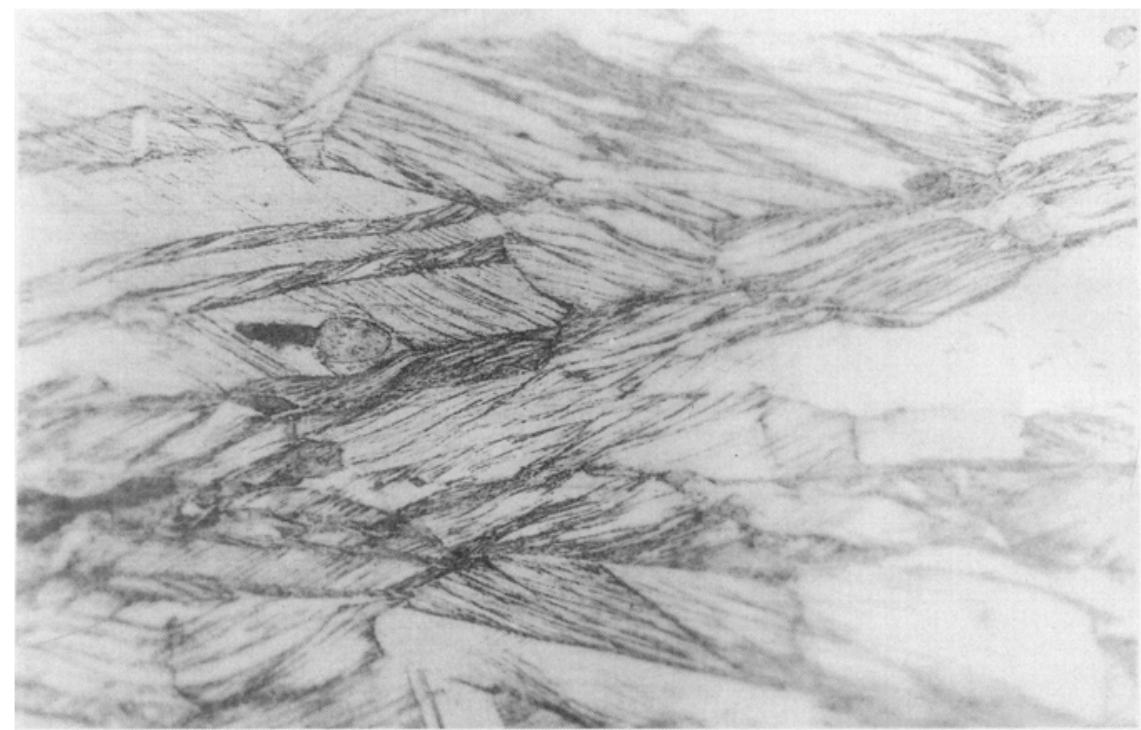

Figure 5. Microstructure of primary aged sample + deformation $60 \%$ (schedule $\left.\mathrm{D}_{1}\right)+$ secondary aged at $270^{\circ} \mathrm{C}(\times 300)$.

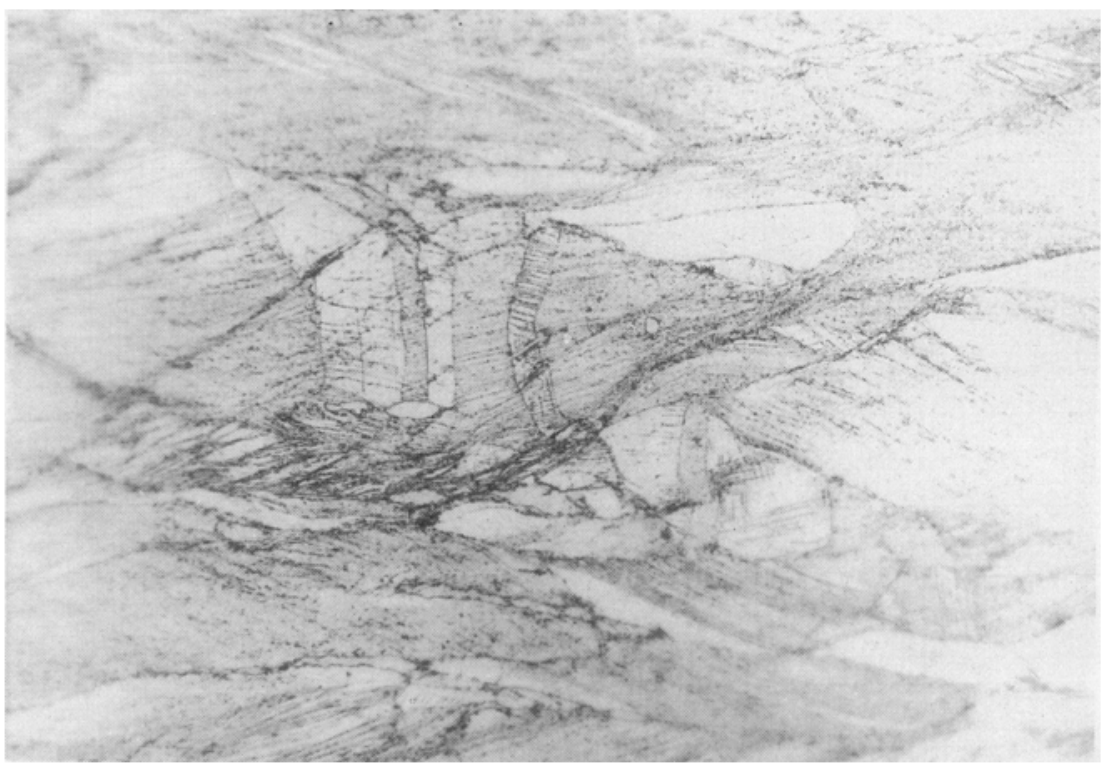

Figure 6. Microstructure of primary aged sample + deformation $60 \%\left(\right.$ schedule $\left.\mathrm{D}_{5}\right)+\mathrm{se}$ condary aged at $270^{\circ} \mathrm{C}(\times 300)$.

than in rolling by high intensity deformation schedule $\mathrm{D}_{5}$ (Severdenko and Gurskii 1972; Markovich et al 1992). Rolling by $D_{1}$ schedule is realized in a large number of passes and the deformation is repeated over relatively small number of active slip systems. This is confirmed by visible shear bands after secondary ageing at $270^{\circ} \mathrm{C}$ in rolled samples by $\mathrm{D}_{1}$ deformation schedule because the precipitate mainly occurred over them (figure 5). Shear bands are not so visible in samples deformed by $\mathrm{D}_{5}$ schedule 


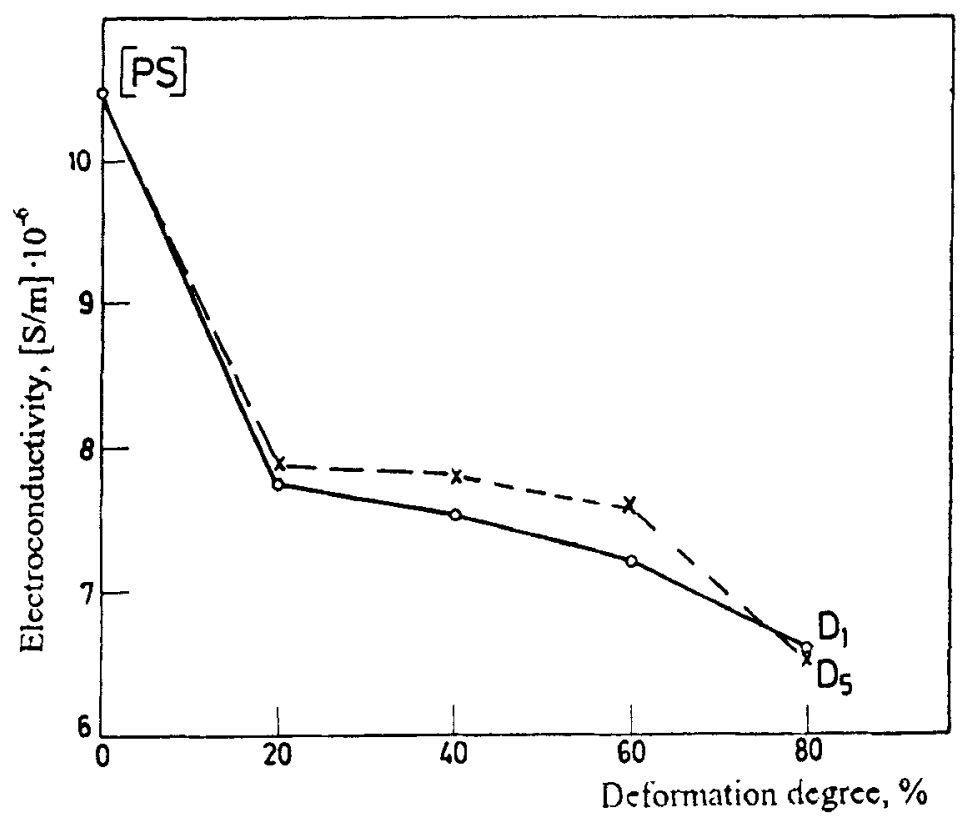

Figure 7. Dependence of electrical conductivity on deformation degree after cold rolling.

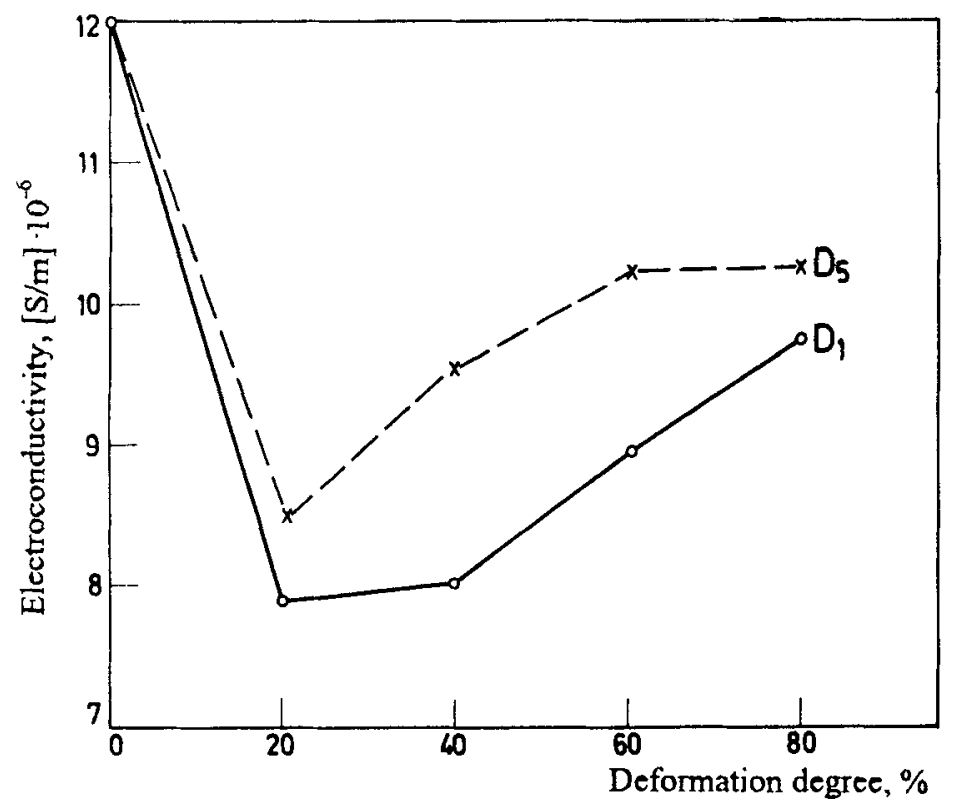

Figure 8. Dependence of electrical conductivity on deformation degree after secondary ageing at $270^{\circ} \mathrm{C}$.

due to activation of a large number of slip systems, and the precipitate is observed both over them and total grain volume (figure 6). This difference in mode and density of precipitation probably has an influence on difference in hardness obtained for $\mathrm{D}_{1}$ and $\mathrm{D}_{5}$ deformation schedules. 


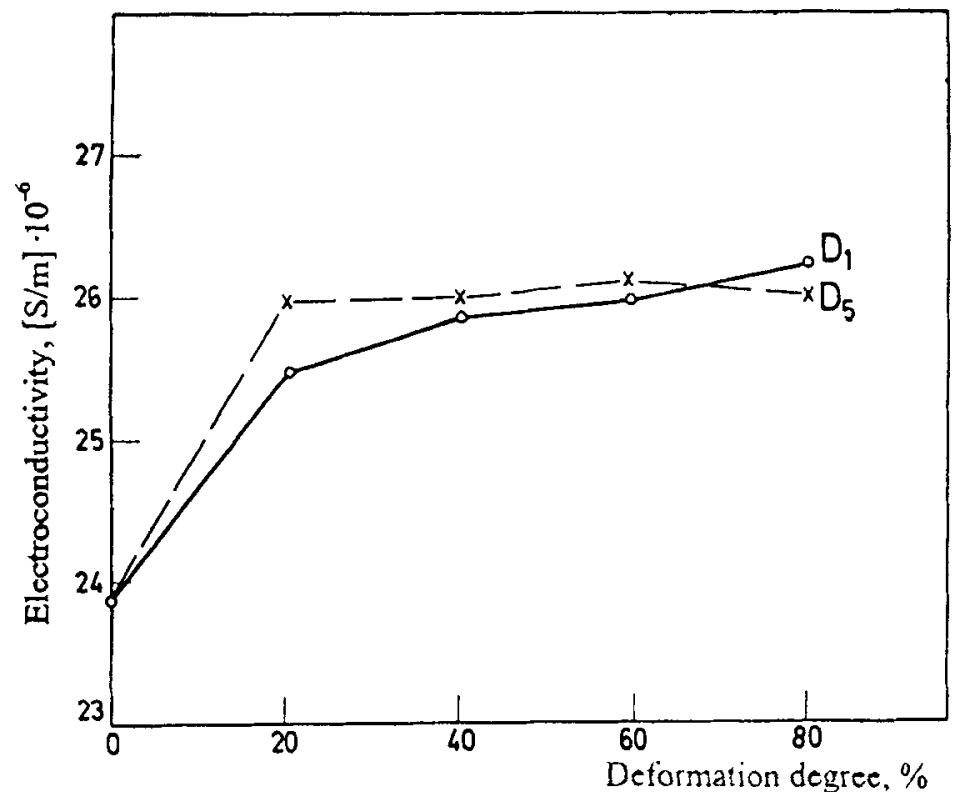

Figure 9. Dependence of electrical conductivity on deformation degree after secondary ageing at $340^{\circ} \mathrm{C}$.

Precipitation from supersaturated solid solution of $\mathrm{CuBe} 2$ alloy can occur continuously as well as discontinuously. A discontinuous reaction starting at original grain boundaries, twin boundaries and deformation bands can be observed as etched areas in an optical microscope (Kreye 1971).

Low intensity deformation schedule probably has an influence on favouring the discontinuous precipitation on slip bands (the metallographic analysis confirms (figure 5)), while the precipitation, after rolling by D5 schedule occurs simultaneously by both mechanisms (discontinuously on shear bands and continuously in grain volume).

The results of electrical conductivity measurement show that the deformation, introduced after primary ageing, accelerates the ageing process. The increase of electrical conductivity, after secondary ageing at $270^{\circ} \mathrm{C}$ with an increase in the degree of previous cold deformation, clearly shows continuous depletion of the alloying elements in the supersaturated solid solution (figure 8).

Acceleration of ageing process by deformation is also shown based on hardness curves (figures 2 and 3). After secondary ageing at $270^{\circ} \mathrm{C}$ in previous rolled samples, the hardness increases with an increase of deformation degree, while the hardness of previous rolled samples, after secondary ageing at $340^{\circ} \mathrm{C}$, is lower than hardness of two-stage aged samples without introduced deformation. Secondary ageing at $340^{\circ} \mathrm{C}$, after rolling, leads to coarsening of precipitate, what is followed by decrease of hardness and further increase of electrical conductivity. The results show that the secondary ageing temperature at $340^{\circ} \mathrm{C}$ is very high for ageing after deformation because it leads to overageing.

Activation energy of ageing process is calculated for all used deformation degrees and both schedules. Two peaks appear on DTA curves of all tested samples 


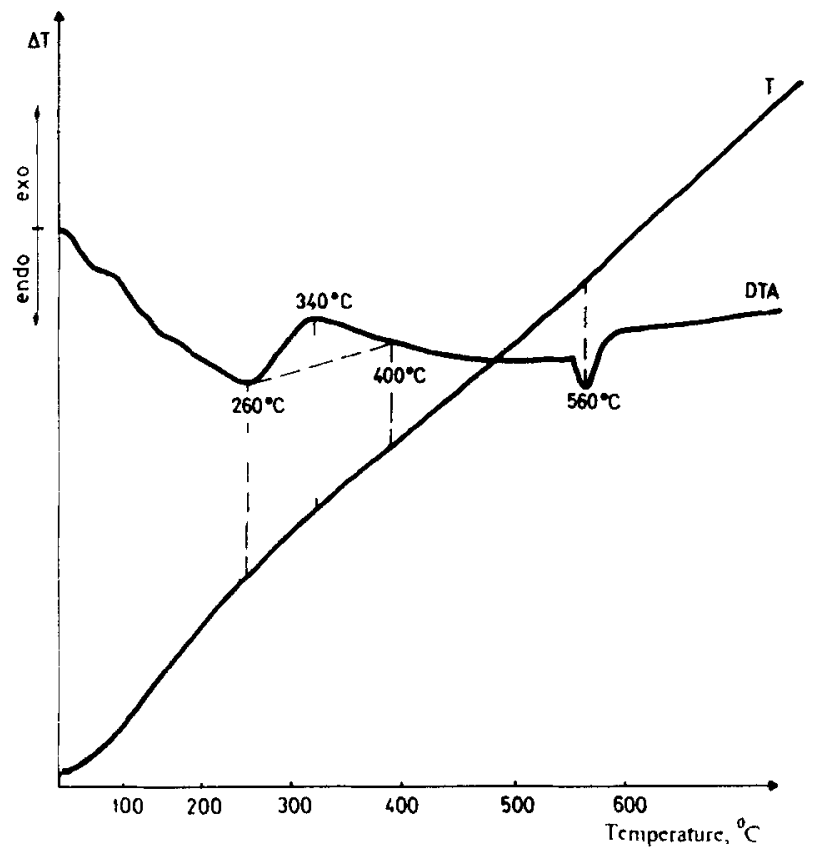

Figure 10. DTA curve for primary aged sample.

(figures 10 and 11). First peak is for exothermic reaction of precipitation process, and the other, which always occurs at $560^{\circ} \mathrm{C}$, corresponds to endothermic process of dissolution. Start and finish of precipitation process depend on the previous deformation degree. For primary aged sample, without previous deformation, start of precipitation is at $260^{\circ} \mathrm{C}$, and the end is at $400^{\circ} \mathrm{C}$ (figure 10). Maximum at first peak, for all deformed samples, is always at $330^{\circ} \mathrm{C}$. Start and end of the peak moves to lower temperatures, clearly for $\mathrm{D}_{1}$ schedule, with an increase of deformation degree. For rolled sample by $\mathrm{D}_{1}$ deformation schedule with $80 \%$ deformation degree, start of precipitation is at $200^{\circ} \mathrm{C}$, and end is at $380^{\circ} \mathrm{C}$ (figure 11), which also confirms that the previous deformation accelerates the precipitation process.

Change of activation energy, depending on degree and deformation schedule, is shown in figure 12. Point on ordinate corresponds to the activation energy of primary aged undeformed sample. The activation energy of ageing process decreases with an increase of deformation degree. Lower values of activation energy are obtained for $D_{1}$ deformation schedule.

It is known that deformation has immediate and subsequent effect on dissolution process of supersaturated solid solution (Bernshtein 1968). The immediate effect is in initiation of dissolution of the supersaturated solid solution during the deformation process and it is determined by mutual effect of dislocation and G. P. zones, formed by primary ageing. During deformation, G. P. zones should partly dissolve and partly stabilize (Markovich et al 1992). The precipitation by continuous mechanism is carried out on stabilized G. P. zones (Bonfield and Edwards 1974).

Subsequent deformation effect is in acceleration of decomposition of the supersaturated solid solution after deformation. It is limited by an increase of appropriate sites for heterogenous nucleation of metastable stages (Bernshtein 1969). 


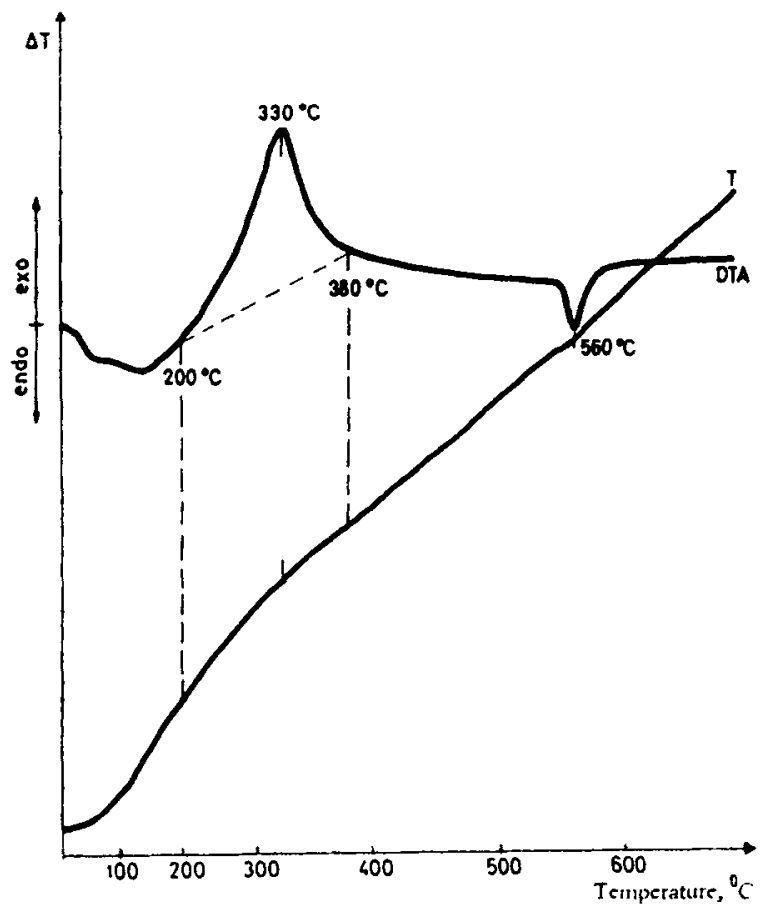

Figure 11. DTA curve for sample deformed at $80 \%$ (schedule $\mathrm{D}_{1}$ ).

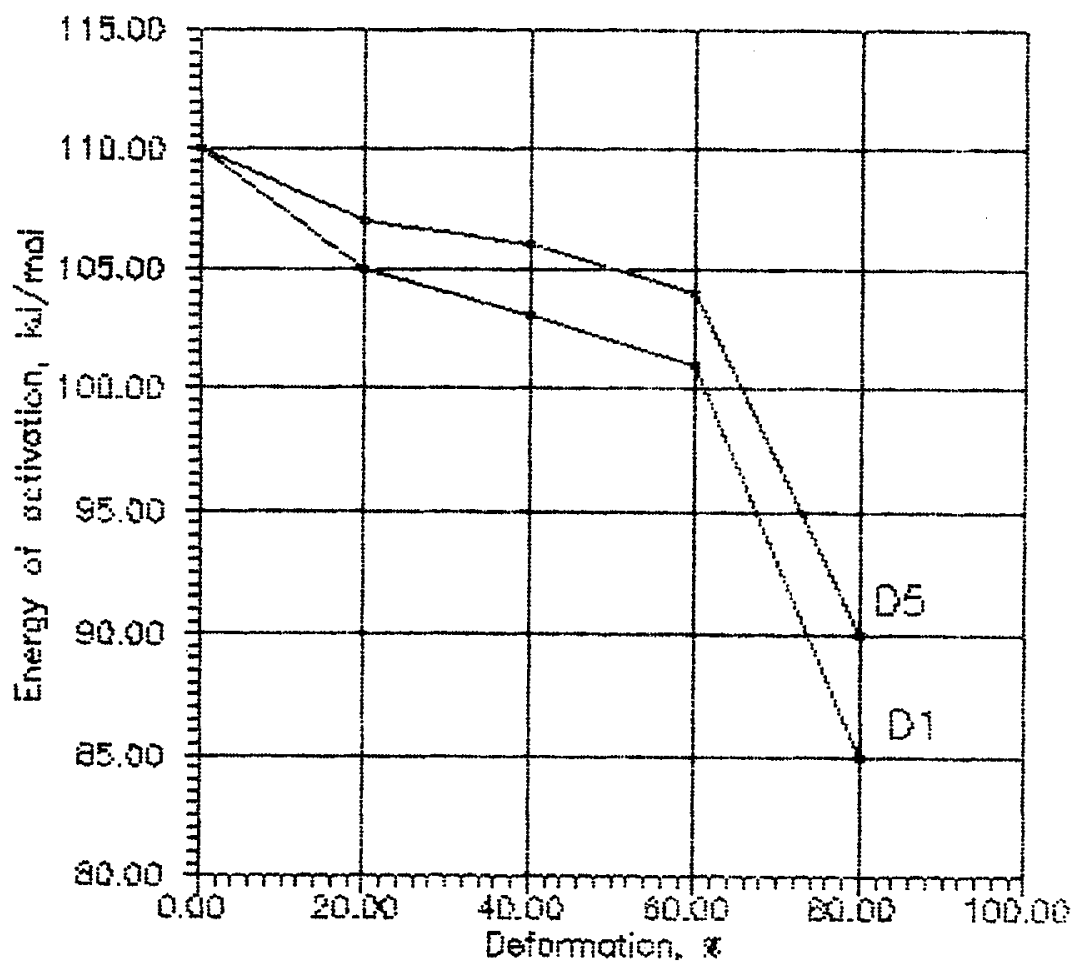

Figure 12. Dependence of activation energy on deformation degree and deformation schedules. 
Lower activation of ageing process in rolled samples by $D_{1}$ schedule should be a consequence of subsequent deformation effect, i.e. higher locally accumulated energy on deformation bands, due to multiple repeated deformation (Nestorovich et al 1994).

\section{Conclusion}

Characteristics of $\mathrm{CuBe} 2$ alloy depend on deformation schedule in thermomechanical treatment and secondary ageing temperature. Difference in precipitation after rolling by $D_{1}$ and $D_{5}$ schedules has an influence on strengthening effect of the alloy, especially after secondary ageing at $270^{\circ} \mathrm{C}$.

Precipitation of $\mathrm{CuBe} 2$ alloy is exothermic process, whose start and finish considerably depend on degree, and depend less on deformation schedule. Start and finish of precipitation process move to lower temperatures with an increase of deformation degree. Plastic deformation decreases activation energy of precipitation process for both used deformation schedules.

\section{References}

Bernshtein M L 1968 Termomechanicheskaya obrabotka metallov i splavov (Moskva: Metallurgiya) Tom 1, p. 270

Bonfield W and Edwards B 1974 J. Mater. Sci. $9398,409,415$

Borchardt H J and Daniels F $1957 \mathrm{~J}$. Am. Ceram. Soc. 7941

Celikov A I 1968 Teoria raschetov usilii v prokatnyh stanah (Moskva: Metallurgizdat) p. 275

Kreye H 1971 Z. Metallkd. 62557

Markovich D, Guskovich D, Nestorovich S and Stoyadinovich S 1992 Phys. Met. Metallogr. 74378

Nestorovich S, Markovich D, Stoyadinovich S and Zhivkovich D 1994 Cvetnye metally 1047

Pastuhova Z P, Gavrilova A V, Masyukov V P and Kaplun Y A 1977 Metally 5154

Rioja R J and Laughlin D E 1980 Acta Metall. 281301

Severdenko V P and Gurskii L I 1972 Struktura v ob'eme i na poverhnosti prokatannyh materialov (Minsk: Nauka i tehnika) p. 41

Zhu F, Mertens P and Wollenberger H 1986 Z. Metallkd. 771 